\title{
Insulin resistance is not associated with myocardial steatosis in women
}

\author{
M. Krššák • Y. Winhofer • C. Göbl • M. Bischof • \\ G. Reiter • A. Kautzky-Willer • A. Luger • M. Krebs • \\ C. Anderwald
}

Received: 26 December 2010 /Accepted: 17 March 2011 /Published online: 15 April 2011

(C) Springer-Verlag 2011

\begin{abstract}
Aims/hypothesis Insulin resistance, an independent riskfactor for cardiovascular disease, precedes type 2 diabetes and is associated with ectopic lipid accumulation in skeletal muscle and liver. Recent evidence indicates that cardiac steatosis plays a central role in the development of diabetic cardiomyopathy. However, it is not known whether insulin resistance as such in the absence of type 2 diabetes is associated with heart steatosis and/or impaired function. We therefore assessed myocardial steatosis and myocardial function in a sample of women with normal insulin sensitivity, insulin resistance, impaired glucose tolerance (IGT) and type 2 diabetes.

Methods Magnetic resonance imaging and localised spectroscopy were used to measure left ventricular dynamic variables and myocardial lipid accumulation in interventricular septum of non-diabetic, age- and BMI-matched insulin-sensitive
\end{abstract}

\footnotetext{
M. Krššák · Y. Winhofer · C. Göbl · M. Bischof $\cdot$

A. Kautzky-Willer $\cdot$ A. Luger $\cdot$ M. Krebs $(\triangle) \cdot$ C. Anderwald

Division of Endocrinology and Metabolism, Department of

Internal Medicine III, Medical University of Vienna,

Währinger Gürtel 18-20,

1090 Wien, Austria

e-mail: michael.krebs@meduniwien.ac.at

M. Krššák

Centre of Excellence, High-Field MR, Department of Radiology,

Medical University Vienna,

Vienna, Austria

\section{Krššák}

Centre for Medical Physics and Biomedical Engineering,

Medical University Vienna,

Vienna, Austria

G. Reiter

Siemens Healthcare,

Vienna, Austria
}

( $n=11,47 \pm 6$ years, BMI $25 \pm 2 \mathrm{~kg} / \mathrm{m}^{2}$; clamp-like index $[$ CLIX] $=9.7 \pm 0.7)$ and insulin-resistant $(n=10,48 \pm 5$ years, $27 \pm 4 \mathrm{~kg} / \mathrm{m}^{2}$; CLIX $=4.5 \pm 0.4$ ) women with normal glucose tolerance as well as of women with IGT $(n=6,45 \pm 5$ years, $\left.28 \pm 6 \mathrm{~kg} / \mathrm{m}^{2} ; \mathrm{CLIX}=3.6 \pm 1.1\right)$ and type 2 diabetes $(n=7,52 \pm$ 10 years, $27 \pm 3 \mathrm{~kg} / \mathrm{m}^{2}$ ).

Results Myocardial lipid content was increased in type 2 diabetic women only (insulin-sensitive $0.4 \pm 0.2 \%$ [means \pm $\mathrm{SD}$; insulin-resistant $0.4 \pm 0.1 \%$; IGT $0.5 \pm 0.2 \%$; type 2 diabetes $0.7 \pm 0.3 \% ; p<0.05)$. In insulin-resistant and type 2 diabetic women, stroke volume was lower $(-15 \%$ and $-27 \%$, respectively, vs insulin-sensitive) and heart rate was higher $(11 \%$ and $14 \%$, respectively, vs insulin-sensitive, $p<0.05)$. No other differences in systolic and diastolic function were observed between study groups.

Conclusions/interpretation In contrast to liver and skeletal muscle, insulin resistance as such is not associated with increased myocardial lipid accumulation.

Keywords Glucose metabolism · Insulin resistance · Magnetic resonance spectroscopy Triacylglycerol
Abbreviations
CLIX Clamp-like index
IGT Impaired glucose tolerance
MRS Magnetic resonance spectroscopy
NA Number of acquisitions
RISC Relationship between Insulin Sensitivity and Cardiovascular Disease Risk

\section{Introduction}

Insulin resistance and type 2 diabetes are closely related to ectopic lipid accumulation in the liver and skeletal muscle 
[1-7]. The combination of insulin resistance and cardiovascular risk factors potentiates the risk of cardiovascular disease and heart failure [8] in patients with type 2 diabetes.

Recent investigations have indicated that a process termed 'lipotoxicity' or 'adipotoxicity' in the heart [9], secondary to increased myocardial lipid accumulation, is likely to underlie the functional and morphological changes that are characterised by concentric left ventricular hypertrophy and to contribute to decreased ventricular compliance and consequently alterations in diastolic function $[10,11]$.

Localised ${ }^{1} \mathrm{H}$-magnetic resonance spectroscopy (MRS) was recently introduced for the non-invasive quantification of intracellular lipids in the human myocardium [12-16] and has identified the association between increased myocardial lipid content and impaired myocardial function $[11,13,17]$. Furthermore, myocardial lipid accumulation has been consistently linked to hyperglycaemia, including impaired glucose tolerance (IGT) [18] and diabetes mellitus [19]. MRI and echocardiography studies have also revealed associations between impaired left ventricular function and insulin resistance [20-23] in large populations spanning from normoglycaemic volunteers to type 2 diabetes patients. These studies suggest a possible causal role of insulin resistance in the development of cardiomyopathy. However, so far it is not known whether, in analogy to skeletal muscle and liver, intracellular lipid content is increased in the heart muscle of insulin-resistant individuals with normal glucose tolerance, thus possibly contributing to early functional defects.

We therefore measured myocardial lipid content and variables of myocardial function in a sample of women, including women with type 2 diabetes and IGT, but also normal glucose-tolerant, insulin-sensitive and insulinresistant volunteers, with a view to correlating these variables with metabolic profile and measures of wholebody insulin sensitivity.

\section{Methods}

\section{Study participants}

Study volunteers were recruited from the local cohort participating in the Relationship between Insulin Sensitivity and Cardiovascular Disease Risk (RISC) Study [24, 25] and the outpatient ward of our department. From the RISC cohort, we selected women with normal glucose tolerance (glucose at $120 \mathrm{~min}$ post challenge $\leq 7.77 \mathrm{mmol} / \mathrm{l}$ ) and with insulin sensitivity from the highest (insulin-sensitive) and lowest (insulin-resistant) quartile of its distribution, as well as women with IGT (normal fasting plasma glucose and insulin concentration, but with 120 min post challenge glucose of 7.77-11.11 mmol/1, $n=3$ ). Additional women with IGT $(n=3)$ and women with type 2 diabetes were recruited from the outpatient ward of our department. In non-diabetic women, glucose metabolism was assessed using standardised OGTT [26] and insulin sensitivity was calculated by the clamp-like index (CLIX) [24], which closely correlates with whole-body insulin sensitivity measured by euglycaemic-hyperinsulinaemic clamps. Exclusion criteria for all participants included: (1) age $>70$ years; (2) known presence of or medical treatment for coronary artery disease; (3) thiazolidinedione therapy; (4) BMI $>32 \mathrm{~kg} / \mathrm{m}^{2}$; and (5) plasma triacylglycerol concentration $>3.4 \mathrm{mmol} / \mathrm{l}$. Of 39 women who were asked to undergo magnetic resonance measurement, five did not respond or refused to participate. All participants gave written informed consent after approval of the study by the local ethics committee.

Altogether we enrolled 11 non-diabetic insulin-sensitive ( $47 \pm 6$ years [mean $\pm \mathrm{SD}$ ], BMI $25 \pm 2 \mathrm{~kg} / \mathrm{m}^{2}$ ), ten insulinresistant $\left(48 \pm 5\right.$ years, $\left.27 \pm 2 \mathrm{~kg} / \mathrm{m}^{2}\right)$, six IGT $(45 \pm 5$ years, $\left.28 \pm 6 \mathrm{~kg} / \mathrm{m}^{2}\right)$ and seven type 2 diabetic women $(52 \pm$ 10 years, $27 \pm 3 \mathrm{~kg} / \mathrm{m}^{2}$ ). Metabolic and clinical variables of the study groups are given in Table 1. None of the women was physically active more than once a week and none had polycystic ovary syndrome. Of the 34 women, 16 were postmenopausal with even distribution between the study groups: insulin-sensitive (five of 11); insulin-resistant (three of ten); and IGT (three of six) groups. The numbers per group who were offspring of type 2 diabetic parents were as follows: type 2 diabetes four of seven; IGT four of six; insulin-sensitive two of 11; and insulin-resistant three of ten. One woman from the insulin-resistant group and four from the type 2 diabetes group were being treated with blood pressure-lowering medication. All participants with type 2 diabetes were being treated with oral glucoselowering medication $(n=4)$ and/or insulin treatment $(n=5)$; two of them were also on lipid-lowering drugs.

Magnetic resonance imaging and spectroscopy

All magnetic resonance measurements were performed on a 3.0-T Tim Trio System (Siemens Healthcare, Erlangen, Germany) operated with a Syngo VB15 (Siemens Healthcare) user interface in the basal metabolic conditions after an overnight fast.

${ }^{1} H$-MRI for myocardial function Visualisation of cardiac function was performed using retrospective ECG-gated cine true fast imaging with steady-state precession (TrueFISP) sequences in two-chamber, four-chamber and short axes orientation. Short axes cine series (typically 11 slices, resolution $1.4 \times 2.1 \times 7.0 \mathrm{~mm}^{3}$, acquisition time per segment $48 \mathrm{~ms}, 25$ reconstructed cardiac phases) were used to quantify left ventricular global function (end-diastolic and 
Table 1 Metabolic characteristics of participating women

Values are mean $\pm \mathrm{SD}$

AU, arbitrary units; IR, insulinresistant; IS, insulin-sensitive; N/A, not assessed; T2DM, type 2 diabetes mellitus

${ }^{*} p<0.05$ vs IS, ${ }^{\dagger} p<0.05$ vs IR, ${ }^{*} p<0.05$ vs IGT

\begin{tabular}{|c|c|c|c|c|}
\hline Characteristic & IS & IR & IGT & $\mathrm{T} 2 \mathrm{DM}$ \\
\hline$n$ & 11 & 10 & 6 & 7 \\
\hline Age (years) & $47 \pm 6$ & $48 \pm 5$ & $45 \pm 5$ & $52 \pm 10$ \\
\hline BMI $\left(\mathrm{kg} / \mathrm{m}^{2}\right)$ & $25.0 \pm 2.2$ & $27.0 \pm 3.6$ & $27.7 \pm 6.1$ & $27.4 \pm 3.1$ \\
\hline $\mathrm{HbA}_{1 \mathrm{c}}(\%)$ & $5.3 \pm 0.3$ & $5.5 \pm 0.3$ & $5.5 \pm 0.3$ & $9.0 \pm 1.9^{*}+\ddagger$ \\
\hline Triacylglycerol (mmol/l) & $1.0 \pm 0.4$ & $1.1 \pm 0.4$ & $1.2 \pm 0.3$ & $2.0 \pm 0.8$ \\
\hline Cholesterol (mmol/l) & $5.5 \pm 0.9$ & $5.7 \pm 0.9$ & $5.8 \pm 0.9$ & $5.7 \pm 1.4$ \\
\hline HDL-cholesterol (mmol/l) & $1.8 \pm 0.4$ & $1.7 \pm 0.5$ & $1.7 \pm 0.3$ & $1.2 \pm 0.3^{* \dagger}$ \\
\hline LDL-cholesterol (mmol/l) & $3.2 \pm 0.8$ & $3.5 \pm 0.6$ & $3.5 \pm 0.8$ & $3.5 \pm 1.0$ \\
\hline \multicolumn{5}{|l|}{ OGTT } \\
\hline AUC glucose $(\mathrm{mmol} / 1 \times \min )$ & $999 \pm 119$ & $1140 \pm 126^{*}$ & $1555 \pm 170^{* \dagger}$ & N/A \\
\hline AUC insulin $\left(\times 10^{3} \mathrm{pmol} / 1 \times \mathrm{min}\right)$ & $33.5 \pm 7.9$ & $62.9 \pm 18.8^{*}$ & $72.2 \pm 29.1^{*}$ & N/A \\
\hline CLIX (AU) & $9.2 \pm 1.7$ & $4.9 \pm 1.0^{*}$ & $3.6 \pm 1.1^{*}$ & N/A \\
\hline Fasting glucose $(\mathrm{mmol} / \mathrm{l})$ & $4.8 \pm 0.3$ & $5.0 \pm 0.3$ & $5.2 \pm 1.0$ & $7.1 \pm 2.0^{*+7}$ \\
\hline Fasting insulin $(\mathrm{pmol} / \mathrm{l})$ & $41 \pm 16$ & $54 \pm 14$ & $40 \pm 38$ & $\mathrm{~N} / \mathrm{A}$ \\
\hline Systolic BP (mmHg) & $119 \pm 13$ & $116 \pm 15$ & $129 \pm 16$ & $136 \pm 29$ \\
\hline Diastolic BP (mmHg) & $78 \pm 10$ & $79 \pm 11$ & $81 \pm 7$ & $79 \pm 7$ \\
\hline
\end{tabular}

end-systolic volume, stroke volume, ejection fraction and myocardial mass) [27] via Argus software (Siemens Healthcare). Ejection fraction was used as the primary index of left ventricular systolic function. In addition, fast low angle shot-based retrospective ECG-gated cine phase velocity encoding sequence (velocity encoding $80 \mathrm{~cm} / \mathrm{s}$, resolution $1.7 \times 2.1 \times 6.0 \mathrm{~mm}^{3}$, acquisition time per segment $71 \mathrm{~ms}, 20$ reconstructed cardiac phases) was used to determine the $\mathrm{E} / \mathrm{A}$ ratio, which is a measure of left ventricular diastolic function and is calculated as the peak velocity ratio between early (passive) filling of the ventricle during diastole (E) and late (due to atrial contraction) mitral inflow (A) [28, 29].

\section{${ }^{1} H$-MRS for quantification of myocardial lipid content} Myocardial lipid measurements were performed using localised ${ }^{1} \mathrm{H}$-MRS based on recently introduced methods [14, 15] (Fig. 1). Anatomical imaging was used to guide watersuppressed point-resolved spectroscopy sequence (echo time TE $30 \mathrm{~ms}$, number of acquisitions (NA)=32). The volume of interest (approximately $6-8 \mathrm{~cm}^{3}$ ) was placed across the middle inter-ventricular septum. The spectral signal was acquired following ECG and navigator-based respiratory triggering using the multichannel cardiac- and spine-reception coils, both of which were provided by the system manufacturer (Siemens Healthcare). Repetition time of the sequence was given by the frequency of breath movement of the individual volunteer. An additional spectrum without water suppression $(\mathrm{NA}=8)$ was used as the internal concentration reference. The spectra were processed by the spectroscopy processing tool provided by the system manufacturer (Siemens Healthcare). The myocardial lipid content was calculated as a ratio of the sum of intensities of
$\left(\mathrm{CH}_{2}\right)_{n}(1.25 \mathrm{ppm})$ and $\mathrm{CH}_{3}(0.8-0.9 \mathrm{ppm})$ group resonances to the intensity of the water resonance from non-water suppressed spectra of the same volume of interest. Intensities of lipid and water resonance lines were corrected for spinlattice $\left(T_{1}\right)$ and spin-spin $\left(T_{2}\right)$ relaxation using individual repetition time and already published $T_{1}$ and $T_{2}$ relaxation times of skeletal muscle at $3 \mathrm{~T}$ [30].

${ }^{1} H$-MRS performance For the assessment of reproducibility and intra-group variation and to give a background for further power calculation, pilot ${ }^{1} \mathrm{H}-\mathrm{MRS}$ measurements of myocardial lipid accumulation were performed in a group of healthy $\left(n=7 ; 49 \pm 5\right.$ years, BMI $\left.27 \pm 2 \mathrm{~kg} / \mathrm{m}^{2}\right)$ and matched type 2 diabetic $\left(n=7 ; 52 \pm 8\right.$ years, BMI $27 \pm 2 \mathrm{~kg} / \mathrm{m}^{2}$ ) women (Fig. 1). Mean intra-individual coefficient of variation on a day-to-day basis reached $39 \%$, which is comparable to the $32 \%$ reported in published data $[14,15]$. Data from two type 2 diabetic patients examined in the pilot performance study were not included in the main study collective, due to pronounced hypertriacylglycerolaemia.

Metabolites, hormones and calculation of insulin sensitivity

The experimental procedures of blood drawing and further analysis of circulating variables were recently described [24]. Individual insulin sensitivity was estimated from the CLIX as described previously [24].

Statistical evaluation

Data are given as mean \pm SD. ANOVA with Dunnett's $t$ post hoc test was performed and significant differences were acknowledged at $p<0.05$. Bivariate and multivariate 
a

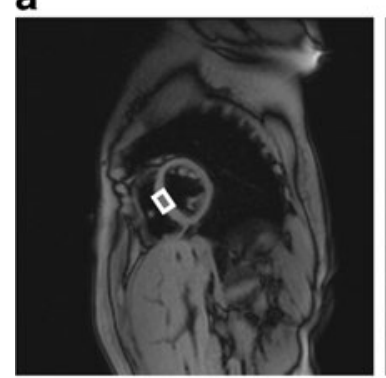

C

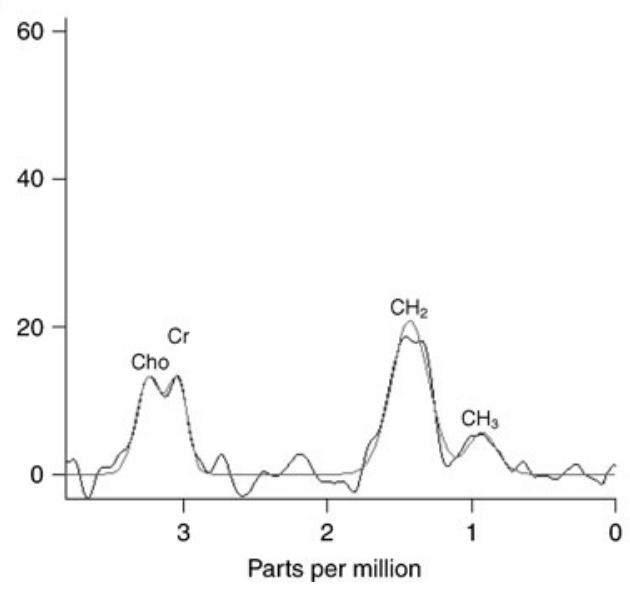

Fig. $1{ }^{1}$ H-MRS of inter-ventricular septum in a healthy woman (a) and a patient with type 2 diabetes (b). White box, localisation of the volume of interest. The acquired spectra (black traces) and results of the line fit (grey traces) in healthy (c) and type 2 diabetic participants

stepwise linear regression analysis (Spearman) was performed to disclose correlation between variables (SPSS 16.0 for Windows; SPSS, Chicago, IL, USA).

\section{Results}

The AUC of plasma glucose concentrations during the OGTT was increased by $14 \%$ (insulin-resistant) and 55\% (IGT) and the AUC of plasma insulin concentrations was $\sim 90 \%$ and $\sim 120 \%$ higher in insulin-resistant and IGT participants respectively compared with insulin-sensitive participants (Table 1). This postprandial hyperinsulinaemia indicates pronounced insulin resistance reflected by a low CLIX in insulin-resistant and IGT participants (Table 1 and Fig. 2.).

Results of functional and metabolite cardiac measurements are summarised in Fig. 2 and Table 2. Left ventricular ejection fraction, end-systolic volume, cardiac output and $\mathrm{E} / \mathrm{A}$ ratio were not different between the groups. Compared with insulin-sensitive participants, stroke volume was lower in insulin-resistant and type 2 diabetic $(-17 \%$ and $-27 \% ; p<0.05)$ participants, and heart rate was higher (insulin-resistant participants $11 \%$, type 2 diabetic $14 \%$; $p<0.05$; Table 2).

\section{b}

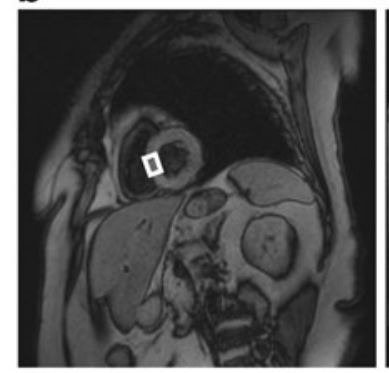

d

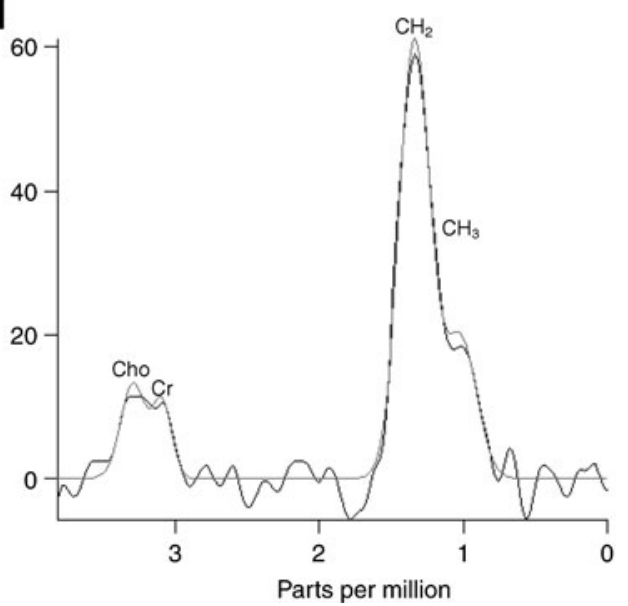

(d) obtained during the performance assessment study. The annotation refers to the methylene $\left(\mathrm{CH}_{2}\right)$ and methyl $\left(\mathrm{CH}_{3}\right)$ groups of fatty acid chains, the $\mathrm{CH}_{3}$ group of creatine $(\mathrm{Cr})$ and total choline-containing compound (Cho)

\section{a}

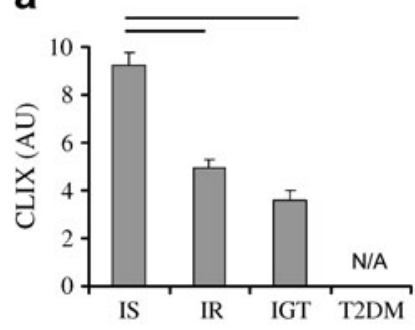

C

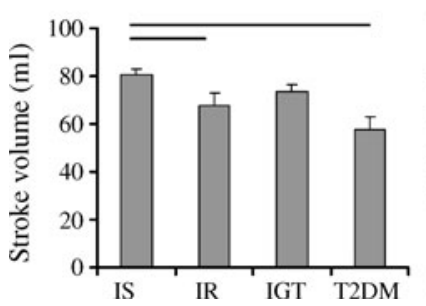

b
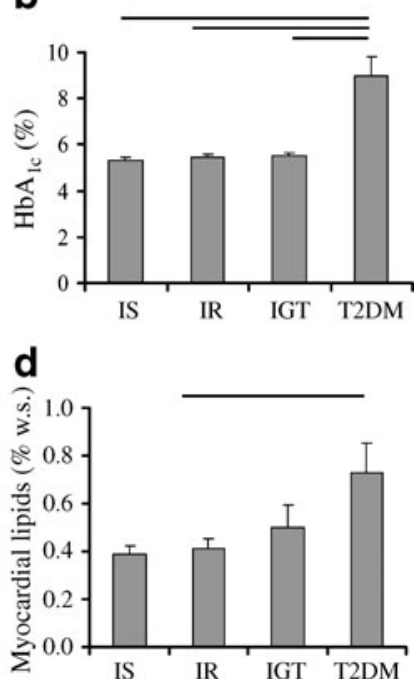

Fig. 2 Measures of (a) insulin sensitivity (CLIX), (b) glycaemia $\left(\mathrm{HbA}_{1 \mathrm{c}}\right),(\mathbf{c})$ cardiac function (stroke volume) and (d) myocardial steatosis in insulin-sensitive (IS), insulin-resistant (IR), IGT and type 2 diabetic (T2DM) study groups. CLIX value (a) in type 2 diabetic participants was not assessed (N/A), as OGTT was performed only in non-diabetic participants. Bold horizontal lines denote significant differences $(p<0.05)$ of the means as revealed by statistical analysis. $\mathrm{AU}$, arbitrary units; w.s., water signal 
Table 2 Left ventricular function variables and myocardial lipid accumulation

Values are mean $\pm \mathrm{SD}$

IR, insulin-resistant; IS, insulin-sensitive; T2DM, type 2 diabetes mellitus

${ }^{*} p<0.05$ vs IS, ${ }^{\dagger} p<0.05$ vs IR

${ }^{\mathrm{a}}$ Per cent of water reference signal

\begin{tabular}{lcccc}
\hline Left ventricular variable & IS & IR & IGT & T2DM \\
\hline Myocardial lipids $^{\mathrm{a}}$ & $0.39 \pm 0.22$ & $0.41 \pm 0.13$ & $0.50 \pm 0.23$ & $0.73 \pm 0.33^{*}$ \\
End diastolic volume (ml) & $114 \pm 18$ & $100 \pm 27^{*}$ & $103 \pm 12$ & $86 \pm 24^{*}$ \\
End systolic volume (ml) & $34 \pm 12$ & $32 \pm 12$ & $29 \pm 6$ & $29 \pm 13$ \\
Stroke volume (ml) & $80 \pm 9$ & $67 \pm 9^{*}$ & $73 \pm 8$ & $58 \pm 14^{*}$ \\
Ejection fraction (\%) & $71 \pm 6$ & $68 \pm 6$ & $71 \pm 4$ & $68 \pm 8$ \\
Heart rate (bpm) & $62 \pm 6$ & $69 \pm 7^{*}$ & $66 \pm 8$ & $71 \pm 9 *$ \\
Cardiac output (1/min) & $5.2 \pm 0.8$ & $4.9 \pm 1.1$ & $4.7 \pm 0.6$ & $4.3 \pm 10.9$ \\
Left ventricular mass (g) & $99 \pm 18$ & $98 \pm 19$ & $95 \pm 13$ & $99 \pm 12$ \\
E/A of mitral flow & $1.3 \pm 0.3$ & $1.5 \pm 0.6$ & $1.4 \pm 0.6$ & $1.1 \pm 0.4$ \\
\hline
\end{tabular}

Multivariable stepwise linear regression on the total study sample $(n=34)$ of stroke volume including $\mathrm{HbA}_{1 \mathrm{c}}$, BMI, HDL-cholesterol, LDL-cholesterol, cholesterol, triacylglycerol, heart rate and myocardial lipid levels identified $\mathrm{HbA}_{1 \mathrm{c}}$ as the strongest and only predictor (Table 4). When participants with type 2 diabetes were excluded (study sample $n=27$ ) and an OGTT-based measure of insulin resistance (CLIX) was included in the set of independent variables, CLIX was identified as the strongest predictor of stroke volume (Table 4). Multivariable stepwise linear regression of myocardial lipids including $\mathrm{HbA}_{1 \mathrm{c}}$, BMI, HDL-cholesterol, LDL-cholesterol, cholesterol, triacylgly-

Table 4 Results of multivariable stepwise regression of stroke volume (dependent variable) and metabolic variables (independent variable) of the total study sample

Table 3 Correlations between metabolic variables and cardiac function or myocardial lipid accumulation in the whole study population as revealed by bivariate correlation analysis (Spearman test)

\begin{tabular}{lcr}
\hline Variable per cardiac feature & Correlation coefficient & $p$ value \\
\hline Stroke volume & & \\
Cardiac output & 0.738 & $<0.001$ \\
HbA $_{1 \mathrm{c}}$ & -0.539 & 0.001 \\
Triacylglycerol & -0.444 & 0.009 \\
HDL-cholesterol & 0.422 & 0.013 \\
CLIX $^{\mathrm{a}}$ & -0.471 & 0.013 \\
Heart rate & -0.403 & 0.018 \\
BMI $_{\text {Cardiac output }}$ & -0.345 & 0.046 \\
HbA $_{1 \mathrm{c}}$ & & \\
CLIX $^{\mathrm{a}}$ & -0.531 & 0.001 \\
Triacylglycerol & -0.493 & 0.009 \\
HDL-cholesterol $_{\text {Myocardial lipids }}$ & -0.375 & 0.029 \\
HbA $_{1 \mathrm{c}}$ & 0.379 & 0.027 \\
AUC glucose OGTT $^{\mathrm{a}}$ & & \\
Triacylglycerol & 0.509 & 0.003 \\
\hline
\end{tabular}

${ }^{a}$ Correlations of OGTT-derived variables proved only on non-diabetic volunteers $(n=27)$

\begin{tabular}{lcc}
\hline Independent variables per stroke volume & $F$ value & $p$ value \\
\hline Stroke volume, total sample $(n=34)$ & & \\
HbA $_{1 c}{ }^{a}$ & 10.816 & 0.003 \\
BMI & $<0.05$ & 0.091 \\
Heart rate & $<0.05$ & 0.201 \\
Triacylglycerol & $<0.05$ & 0.294 \\
Myocardial lipids & $<0.05$ & 0.302 \\
HDL-cholesterol & $<0.05$ & 0.498 \\
LDL-cholesterol & $<0.05$ & 0.584 \\
Cholesterol & $<0.05$ & 0.768 \\
Stroke volume, no T2DM sample $(n=27)$ & & \\
CLIX & \\
HbA & & \\
HDL-cholesterol & 4.957 & 0.035 \\
Heart rate & $<0.05$ & 0.134 \\
Cholesterol & $<0.05$ & 0.280 \\
Triacylglycerol & $<0.05$ & 0.378 \\
BMI & $<0.05$ & 0.599 \\
Myocardial lipids & $<0.05$ & 0.783 \\
LDL-cholesterol & $<0.05$ & 0.828 \\
\hline
\end{tabular}

${ }^{\mathrm{a}}$ Variables accepted into the model; all other variables not accepted into model 
cerol, heart rate, AUC glucose and CLIX did not reveal any single significant predictor.

\section{Discussion}

We have measured left ventricular function by cardiac MRI and myocardial lipid content by MRS in 34 women with a broad range of metabolic characteristics spanning from healthy, non-diabetic with and without insulin resistance through to IGT and type 2 diabetes mellitus. Whereas intramyocardial lipid stores were clearly higher in women with overt hyperglycaemia (i.e. type 2 diabetes), insulin resistance as such was not associated with increased myocardial lipid content.

Our results complete previous observations of increased myocardial lipid accumulation in prediabetic states including non-diabetic obesity and IGT and/or hyperglycaemia $[18,19,31,32]$. In these studies, populations with a broad range of BMI were included. Patients presented with increased BMI $\left(>31 \mathrm{~kg} / \mathrm{m}^{2}\right)$ in comparison to rather lean control groups $\left(<23 \mathrm{~kg} / \mathrm{m}^{2}\right)$ [19]. Along with BMI [32], insulin sensitivity estimated by HOMA of insulin resistance, fasting and post-challenge (OGTT) hyperglycaemia were identified as predictors of myocardial lipid accumulation [18] and left ventricular remodelling [21].

In contrast to those studies [18, 19, 21-23], careful BMIand age-matching of insulin-sensitive and insulin-resistant women allowed us to focus and draw conclusions on the role of insulin resistance. We observed subtle associations between variables of myocardial function and long term glycaemia $\left(\mathrm{HbA}_{1 \mathrm{c}}\right)$, insulin resistance (CLIX), triacylglycerol and cholesterol concentrations. The decrease in left ventricular stroke volume in the insulin-resistant group $(-17 \% ; p=0.037)$ was counteracted by an increased heart rate $(11 \%, p=0.030)$, yielding no difference in cardiac output between the groups. However, no effect of insulin resistance as such on myocardial lipid content was observed. Based on previously published data $[15,31]$ and our pilot measurements, the present study was sufficiently powered to detect relevant variations in myocardial lipid content in the range of differences reported not only for patients with overt diabetes, but also for those with other insulin resistance stages including obesity [18]. However, the conclusion that functional adaptations including decreased stroke volume might precede lipid accumulation has to be drawn with caution, since the sensitivity of MRI for detection of subtle changes in myocardial function is likely to exceed the sensitivity of MRS employed to measure myocardial lipid stores.

So far the mechanisms responsible for cardiac steatosis have been addressed mainly in animal studies. It appears that, in diabetic rodents, cardiac fatty acid uptake and metabolism are increased secondary to elevated plasma NEFA concentrations and increased protein levels of fatty acid transporters. A proportion of elevated cytosolic longchain fatty acids are incorporated into the myocardial lipid pool, leading to elevated concentrations of intracellular triacylglycerol, diacylglycerol and ceramides [33]. Augmented oxidation of fatty acids results in increased generation of reactive oxygen species, leading to mitochondrial dysfunction, which might contribute to impaired contractility [34]. These studies illustrate that the myocardial triacylglycerol pool is dynamic, but they do not prove that triacylglycerol accumulation directly influences cardiac function. However, cardiac steatosis is an important biomarker for the underlying defects described above [9]. Mitochondrial dysfunction, which is associated with insulin-resistant states, might not only be the consequence, but could also be the cause of intramyocellular lipid deposition. It has been proposed that reduced rates of mitochondrial oxidative phosphorylation predispose to lipid accumulation in skeletal muscle [35]. Furthermore, increased intracellular availability of glucose (secondary to hyperglycaemia and hyperinsulinaemia) has been shown to inhibit fatty acid oxidation mediated by increased malonylCoA concentrations [36]. Thus increased availability of circulating fatty acids, augmented transporter-mediated cellular uptake of fatty acids, impaired lipid oxidation secondary to hyperglycaemia, and mitochondrial dysfunction might all contribute to myocardial lipid accumulation.

The precise mechanisms mediating myocardial steatosis and diabetic heart disease in humans have not yet been elucidated. Short-term elevation of plasma NEFA secondary to energy intake restriction has been associated with increased accumulation of myocardial triacylglycerol [14, 17], but a single fat-rich meal and 3 days of high-fat diet did not affect myocardial triacylglycerol content $[14,37]$. In long-term interventional studies, 12 weeks of combined exercise training [38] and 6-month treatment with pioglitazone and insulin [39] reduced myocardial steatosis and $\mathrm{HbA}_{1 \mathrm{c}}$ in healthy obese and type 2 diabetic patients, respectively. On the other hand, van der Meer et al. [40] were unable to detect a decrease in myocardial lipid accumulation, despite improved glycaemic control, wholebody insulin sensitivity, left ventricular stroke volume and early peak flow rate, during pioglitazone therapy in type 2 diabetic patients. The controversial results of these studies left the question of a possible link between insulin resistance and cardiac steatosis unanswered.

One potential limitation of our study is the restriction to female participants. The stratification of our study collective was led by the results of previously published studies suggesting women to be more susceptible than men to unfavourable effects of hyperglycaemia with regard to cardiovascular conditions. Thus the Framingham study 
reported that women with diabetes are at double the risk of developing heart failure compared with their male counterparts [41]. Increased cardiovascular risk is already present in premenopausal type 2 diabetic women, suggesting that diabetes abolishes the protection of female sex hormones against cardiovascular diseases [42]; moreover, increased intramyocardial lipid content is more pronounced in women with overt hyperglycaemia than in comparable men [18]. It thus appears that female hearts might be especially susceptible to the diabetes-specific environment. The limited number of women with IGT included in the study resulted from the extremely low prevalence of this condition in the population of otherwise healthy women. Nevertheless, the inclusion of BMI- and agematched IGT and type 2 diabetic women allowed us to perform bivariate correlation analysis, which suggested links between myocardial lipid accumulation and longterm $\left(\mathrm{HbA}_{1 \mathrm{c}}\right)$ or acute hyperglycaemia (AUC glucose OGTT) and plasma triacylglycerol levels. However, neither insulin resistance (CLIX) nor $\mathrm{HbA}_{1 \mathrm{c}}$ were selected as independent predictors of myocardial lipid content by multivariable linear regression.

Taken together, this cross-sectional study suggests that insulin resistance as such is not associated with increased myocardial lipid content.

Acknowledgements The authors would like to acknowledge logistic support from S. Trattnig and E. Moser (Centre-of-Excellence High Field MR, Medical University of Vienna). We also thank Siemens Healthcare, especially J. Xu, N. Salibi and U. Boettcher, for providing point-resolved spectroscopy sequence enabling dual triggering of ${ }^{1} \mathrm{H}$ MRS data acquisition. The study was supported by the Jubiläumsfond of Austrian National Bank (grant no. 13249 to M. Krššák).

Duality of interest The authors declare that there is no duality of interest associated with this manuscript.

\section{References}

1. Krebs M, Roden M (2005) Molecular mechanisms of lipidinduced insulin resistance in muscle, liver and vasculature. Diabetes Obes Metab 7:621-632

2. Jacob S, Machann J, Rett K et al (1999) Association of increased intramyocellular lipid content with insulin resistance in lean nondiabetic offspring of type 2 diabetic subjects. Diabetes 48:1113-1119

3. Kautzky-Willer A, Krssak M, Winzer C et al (2003) Increased intramyocellular lipid concentration identifies impaired glucose metabolism in women with previous gestational diabetes. Diabetes $52: 244-251$

4. Krssak M, Falk Petersen K, Dresner A et al (1999) Intramyocellular lipid concentrations are correlated with insulin sensitivity in humans: a ${ }^{1} \mathrm{H}$ NMR spectroscopy study. Diabetologia 42:113-116

5. Krssak M, Roden M (2004) The role of lipid accumulation in liver and muscle for insulin resistance and type 2 diabetes mellitus in humans. Rev Endocr Metab Disord 5:127-134
6. Perseghin G, Scifo P, De Cobelli F et al (1999) Intramyocellular triglyceride content is a determinant of in vivo insulin resistance in humans: a ${ }^{1} \mathrm{H}-{ }^{13} \mathrm{C}$ nuclear magnetic resonance spectroscopy assessment in offspring of type 2 diabetic parents. Diabetes 48:1600-1606

7. Vega GL, Chandalia M, Szczepaniak LS, Grundy SM (2007) Metabolic correlates of nonalcoholic fatty liver in women and men. Hepatology 46:716-722

8. de Simone G, Devereux RB, Chinali M et al (2009) Metabolic syndrome and left ventricular hypertrophy in the prediction of cardiovascular events: the Strong Heart Study. Nutr Metab Cardiovasc Dis 19:98-104

9. Wende AR, Abel ED (2009) Lipotoxicity in the heart. Biochim Biophys Acta 1801:311-319

10. Taegtmeyer H (2004) Cardiac metabolism as a target for the treatment of heart failure. Circulation 110:894-896

11. Rijzewijk LJ, van der Meer RW, Smit JW et al (2008) Myocardial steatosis is an independent predictor of diastolic dysfunction in type 2 diabetes mellitus. J Am Coll Cardiol 52:1793-1799

12. den Hollander JA, Evanochko WT, Pohost GM (1994) Observation of cardiac lipids in humans by localized ${ }^{1} \mathrm{H}$ magnetic resonance spectroscopic imaging. Magn Reson Med 32:175-180

13. Szczepaniak LS, Dobbins RL, Metzger GJ et al (2003) Myocardial triglycerides and systolic function in humans: in vivo evaluation by localized proton spectroscopy and cardiac imaging. Magn Reson Med 49:417-423

14. Reingold JS, McGavock JM, Kaka S, Tillery T, Victor RG, Szczepaniak LS (2005) Determination of triglyceride in the human myocardium by magnetic resonance spectroscopy: reproducibility and sensitivity of the method. Am J Physiol Endocrinol Metab 289:E935-E939

15. van der Meer RW, Doornbos J, Kozerke S et al (2007) Metabolic imaging of myocardial triglyceride content: reproducibility of ${ }^{1} \mathrm{H}$ MR spectroscopy with respiratory navigator gating in volunteers. Radiology 245:251-257

16. Felblinger J, Jung B, Slotboom J, Boesch C, Kreis R (1999) Methods and reproducibility of cardiac/respiratory doubletriggered (1)H-MR spectroscopy of the human heart. Magn Reson Med 42:903-910

17. van der Meer RW, Hammer S, Smit JW et al (2007) Short-term caloric restriction induces accumulation of myocardial triglycerides and decreases left ventricular diastolic function in healthy subjects. Diabetes 56:2849-2853

18. Iozzo P, Lautamaki R, Borra R et al (2009) Contribution of glucose tolerance and gender to cardiac adiposity. J Clin Endocrinol Metab 94:4472-4482

19. McGavock JM, Lingvay I, Zib I et al (2007) Cardiac steatosis in diabetes mellitus: a ${ }^{1} \mathrm{H}$-magnetic resonance spectroscopy study. Circulation 116:1170-1175

20. Bajraktari G, Koltai MS, Ademaj F et al (2006) Relationship between insulin resistance and left ventricular diastolic dysfunction in patients with impaired glucose tolerance and type 2 diabetes. Int J Cardiol 110:206-211

21. Velagaleti RS, Gona P, Chuang ML et al (2010) Relations of insulin resistance and glycemic abnormalities to cardiovascular magnetic resonance measures of cardiac structure and function: the Framingham Heart Study. Circ Cardiovasc Imaging 3:257-263

22. Bertoni AG, Goff DC Jr, D'Agostino RB Jr et al (2006) Diabetic cardiomyopathy and subclinical cardiovascular disease: the MultiEthnic Study of Atherosclerosis (MESA). Diabetes Care 29:588594

23. Heckbert SR, Post W, Pearson GD et al (2006) Traditional cardiovascular risk factors in relation to left ventricular mass, volume, and systolic function by cardiac magnetic resonance imaging: the Multiethnic Study of Atherosclerosis. J Am Coll Cardiol 48:2285-2292 
24. Anderwald C, Anderwald-Stadler M, Promintzer M et al (2007) The Clamp-Like Index: a novel and highly sensitive insulin sensitivity index to calculate hyperinsulinemic clamp glucose infusion rates from oral glucose tolerance tests in nondiabetic subjects. Diabetes Care 30:2374-2380

25. Promintzer M, Krebs M, Todoric J et al (2007) Insulin resistance is unrelated to circulating retinol binding protein and protein $\mathrm{C}$ inhibitor. J Clin Endocrinol Metab 92:4306-4312

26. Anderwald C, Pfeiler G, Nowotny P et al (2008) Glucose turnover and intima media thickness of internal carotid artery in type 2 diabetes offspring. Eur J Clin Investig 38:227-237

27. Barkhausen J, Ruehm SG, Goyen M, Buck T, Laub G, Debatin JF (2001) MR evaluation of ventricular function: true fast imaging with steady-state precession vs fast low-angle shot cine MR imaging: feasibility study. Radiology 219:264-269

28. Mohiaddin RH, Amanuma M, Kilner PJ, Pennell DJ, Manzara C, Longmore DB (1991) MR phase-shift velocity mapping of mitral and pulmonary venous flow. J Comput Assist Tomogr 15:237-243

29. van der Meer RW, Diamant M, Westenberg JJ et al (2007) Magnetic resonance assessment of aortic pulse wave velocity, aortic distensibility, and cardiac function in uncomplicated type 2 diabetes mellitus. J Cardiovasc Magn Reson 9:645-651

30. Krssak M, Mlynarik V, Meyerspeer M, Moser E, Roden M (2004) ${ }^{1} \mathrm{H}$ NMR relaxation times of skeletal muscle metabolites at $3 \mathrm{~T}$. MAGMA 16:155-159

31. McGavock JM, Victor RG, Unger RH, Szczepaniak LS (2006) Adiposity of the heart, revisited. Ann Intern Med 144:517-524

32. Szczepaniak LS, Victor RG, Orci L, Unger RH (2007) Forgotten but not gone: the rediscovery of fatty heart, the most common unrecognized disease in America. Circ Res 101:759-767

33. Heather LC, Clarke K (2011) Metabolism, hypoxia and the diabetic heart. J Mol Cell Cardiol 50:598-605
34. Bugger H, Abel ED (2008) Molecular mechanisms for myocardial mitochondrial dysfunction in the metabolic syndrome. Clin Sci (Lond) 114:195-210

35. Morino K, Petersen KF, Shulman GI (2006) Molecular mechanisms of insulin resistance in humans and their potential links with mitochondrial dysfunction. Diabetes 55(Suppl 2):S9-S15

36. Hue L, Taegtmeyer H (2009) The Randle cycle revisited: a new head for an old hat. Am J Physiol Endocrinol Metab 297:E578E591

37. van der Meer RW, Hammer S, Lamb HJ et al (2008) Effects of short-term high-fat, high-energy diet on hepatic and myocardial triglyceride content in healthy men. J Clin Endocrinol Metab 93:2702-2708

38. Schrauwen-Hinderling VB, Hesselink MK, Meex R et al (2010) Improved ejection fraction after exercise training in obesity is accompanied by reduced cardiac lipid content. J Clin Endocrinol Metab 95:1932-1938

39. Zib I, Jacob AN, Lingvay I et al (2007) Effect of pioglitazone therapy on myocardial and hepatic steatosis in insulin-treated patients with type 2 diabetes. J Investig Med 55:230-236

40. van der Meer RW, Rijzewijk LJ, de Jong HW et al (2009) Pioglitazone improves cardiac function and alters myocardial substrate metabolism without affecting cardiac triglyceride accumulation and high-energy phosphate metabolism in patients with well-controlled type 2 diabetes mellitus. Circulation 119:20692077

41. Kannel WB, Hjortland M, Castelli WP (1974) Role of diabetes in congestive heart failure: the Framingham Study. Am J Cardiol 34:29-34

42. Legato MJ, Gelzer A, Goland R et al (2006) Gender-specific care of the patient with diabetes: review and recommendations. Gend Med 3:131-158 